\title{
Oxidative Stress Levels in Buccal Cells Using MAWI Collection Tubes
}

Sandy-Belle Tabbouny ${ }^{1}$, Elinora Chamoun ${ }^{2}$, Nataliia Pavliuchenko ${ }^{2}$ and Marcel Bassil ${ }^{1,2^{*}}$

${ }^{1}$ Faculty of Science, Lebanese University, Rafic Hariri University Campus, Hadath, Lebanon

${ }^{2}$ Biotechnology Department, Benta Pharma Industries, Dbayeh, Lebanon

*Corresponding author: Marcel Bassil, Faculty of Science, Lebanese University, Rafic Hariri University Campus, Hadath, Lebanon, Tel: 96171921665; E-mail: marcel.bassil@hotmail.com

Received date: February 17, 2017; Accepted date: February 26, 2017; Published date: February 28, 2017

Copyright: (c) 2017 Tabbouny SB, et al. This is an open-access article distributed under the terms of the Creative Commons Attribution License, which permits unrestricted use, distribution, and reproduction in any medium, provided the original author and source are credited.

\begin{abstract}
Background: Oxidative Stress (OS) is defined as an imbalance between oxidants and antioxidants, in favor of oxidants, potentially leading to DNA damage. Benzo[a] pyrene $(\mathrm{B}(\mathrm{a}) \mathrm{P})$, a representative DNA-damaging mutagenic/ carcinogenic Polycyclic Aromatic Hydrocarbons (PAH), can lead to the final mutagen Benzo(a)Pyrene Diol Epoxide (BPDE).

Methods: The extent of oxidative DNA damage is investigated in population studies using easily obtained cells. Buccal cell usage has been shown by many to be a cost effective, non-invasive and safe method to isolate DNA for various biological experiments. In this experimental research of 40 participants, equally divided between industry and academia, we compared the DNA concentration, purity, and associated levels of BPDE-DNA damage. Buccal cells were collected using ISWAB-DNA tubes, and DNA was then extracted to study the extent of DNA damage via ELISA Kit.
\end{abstract}

Results: Results showed pure samples with no DNA degradation. DNA yields were as high as $35.657 \mu \mathrm{g} / \mathrm{mL}$. In addition, none of the samples showed a presence of BPDE-DNA damage.

Conclusions: MAWI collection tubes may not be able to detect BPDE-DNA damage. Other OS markers should be used to eradicate the previous statement.

Keywords Oxidative stress; iSWAB tubes; DNA damage; Buccal swabs; Benzo(a)Pyrene Diol Epoxide (BPDE)

\section{Introduction}

DNA is susceptible to many kinds of damage and one of these is oxidative damage. The accumulation of Reactive Oxygen/Nitrogen Species (RONS) can result in a number of detrimental effects such as lipid peroxidation, protein oxidation, and DNA damage. Respecting to oxidative stress-induced DNA damage, it is estimated that OS may induce approximately 10,000 DNA alterations per cell per day which represents a major portion of endogenous DNA damage [1]. B(a)P, a representative DNA-damaging mutagenic/carcinogenic $\mathrm{PAH}$, is present in polluted air, cooked foods and cigarette smoke $[2,3]$. The toxicity of some PAHs has been demonstrated to induce malignant tumors in animal models and is also commonly believed to significantly contribute to human cancers. One $\mathrm{PAH}$ compound, $\mathrm{B}(\mathrm{a}) \mathrm{P}$, is notable for being the first chemical carcinogen to be discovered. It is a five-ring PAH known to be a procarcinogen; its mechanism of carcinogenesis is dependent on a 3-step enzymatic metabolism (Figure 1) to the final mutagen BPDE. Very reactive, BPDE binds covalently to the structure of proteins, RNA and DNA (guanine residues) [4,5]. The complex of reactive metabolite and DNA structure is known as a DNA adduct. In the case of BPDE it is a BPDE-DNA adduct [6]. If left unrepaired, DNA adducts may lead to permanent mutations resulting in cell transformation and ultimately tumor development.



Figure 1: B(a)P catalyzed to various metabolites by CYP450 enzymes and epoxide hydrolase (EH), resulting in the final carcinogen BPDE. 
The usage of buccal cells has been shown by many to be a cost effective, non-invasive and safe method to isolate DNA for various biological experiments, especially large epidemiological studies. On the other hand, a disadvantage for the use of buccal cells is DNA contamination. In fact, the procedures using buccal cells strictly define that the subject rinse his or her mouth thoroughly before buccal cell collection and stop eating or drinking anything at least $30 \mathrm{~min}$ prior to the swabbing but an overwhelming number of people do not exactly follow the restrictions which leads to erroneous results due to the contamination of non-human DNA in buccal samples. Although buccal cells provides a smaller amount of DNA than blood, recently developed methods of genotyping use very small amounts of DNA (2-10 ng per assay) and thus allow the use of buccal cells as a source of DNA. Importantly, the use of non-invasive DNA collection methods has been shown to increase study participation rates [7].

Different methods for DNA collection from buccal cells have been evaluated like cytobrush, mouthwash, treated cards, whole saliva collection, swabs, in order to assess the quantity and quality of DNA and the feasibility and cost of the procedures. DNA buccal swabs have been specifically designed to increase study participation and compliance in research centers and for sick patients in hospital settings. In fact, the cotton swab has long been a basic and essential tool for collecting DNA evidence for forensic casework analysis [7].

The innovative design of iSWAB tubes allows for removal of the cells captured by the cotton mouth swab and then released into a proprietary lysis and nucleic acid stabilizing buffer. The combination of the mechanistic release of cells and proprietary lysis buffer allows for the collection of high amount of cells in a concentrated manner, in a small amount of lysis buffer, while yielding significantly low bacterial contamination. ISWAB tubes can be used to collect DNA, RNA, protein, cell or blood samples for animals and humans. For DNA sampling, ISWAB-DNA devices are mainly used in Forensics; they are useful for DNA profiling, fingerprinting suspects and mass populations, genetic research, forensic research, epidemiologic study, PCR, sequencing/genotyping assays, gene expression, etc. They are used in this study for many reasons. It is a simple, fast and convenient sample collection that can be done by the person himself or assisted with high simplicity, in less than 5 mints. It shows a low bacterial genomic DNA contamination $(<1 \%)$ and a high nucleic acid recovery. ISWAB-DNA tubes are stable at room temperature which reduces sample storage and transport costs by eliminating cold chain, and easy to process. In addition, they are suitable for all population segments including infants, toddlers, and elderly. In this study, we will evaluate the levels of DNA oxidation from buccal cells using a novel DNA collection sample called iSWAB DNA tubes. Also, we will try to see if there is a difference in levels of oxidative stress between academic and industrial workers.

\section{Materials and Methods}

\section{Selection of subjects}

A group of 40 healthy adult volunteers was recruited (age range, 20-54 years): 20 from the Faculty of Science, Lebanese University, Rafic Hariri University Campus, Hadath, Lebanon and the Faculty of Science, Lebanese University, Fanar Campus, Lebanon; and 20 others from Benta Pharma Industries BPI, Dbayeh, Lebanon. The samples were totally anonymous with no connection between results and volunteer identity. Inclusion criteria were non heavy smokers, no heavy alcohol consumption, non-obese, and absence of chronic or acute diseases, as assessed by self-reports. Volunteer's written informed consent was obtained before study participation. The detailed informed consent and questionnaire are provided at the end of the study.

The academic group was subdivided into 2 subgroups A and B: the 10 samples of the subgroup A were collected from the Faculty of Science, Lebanese University, Rafic Hariri University Campus, Hadath, Lebanon; and the 10 others of the subgroup B were collected from the Lebanese University, Faculty of Science, Fanar Campus, Lebanon. And the group of volunteers collected from Benta Pharma Industries BPI, Dbayeh, Lebanon was also subdivided into 2 subgroups $\mathrm{C}$ and D.

\section{Materials}

MAWI tubes were taken from Benta Trading, the QIAamp DNA Mini Kit was obtained from QIAGEN (Germany) and the Ethanol 99.8\% was purchased from Sigma-Aldrich. For the preparation of the gel: Agarose and Tris-base were obtained from Sigma; Ethylenediaminetetraacetic Acid (EDTA) and Boric acid were purchased from HIMEDIA; $\mathrm{NaOH} 45 \%$ was obtained from Merck and Ethidium Bromide (EtBr) from Usb. ELISA kit was purchased from My BioSource.

\section{Buccal cell collection technique}

The volunteers recruited were asked to refrain from eating/drinking at least 30 mints prior to the swabbing, to avoid the contamination with food particles. For each individual, buccal cells were collected on a cotton mouth swab by twirling it on the inner cheek firmly for 20 times, the operation was repeated two times for each subject, on the two cheeks. And the total of four samples was collected from both sides and completely released into a lysis and nucleic acid stabilizing buffer contained in iSWAB-DNA $1 \mathrm{~mL}$ tubes.

\section{Sample processing}

Each of the samples contained in iSWAB-DNA tubes was stored at room temperature $\left(15-25^{\circ} \mathrm{C}\right)$ for one day before the DNA extraction step.

DNA extraction: DNA extraction was performed using a QIAamp DNA Mini Kit (Cat\#154018529) according to the manufacturer's protocol. Buccal cells were used for the extraction $(250 \mu \mathrm{L}$ per column, except the subgroup A from which was taken $200 \mu \mathrm{L}$ ). Extracted DNA was kept at $-20^{\circ} \mathrm{C}$ until use.

DNA quantification: Absorbance readings were performed at 260 $\mathrm{nm}, 280 \mathrm{~nm}$ and $320 \mathrm{~nm}$. DNA concentration was estimated by measuring the absorbance at $260 \mathrm{~nm}$ (A260) and adjusting it for turbidity (measured by A320), multiplying by the dilution factor (DF), and using the relationship that an A260 of $1.0=50 \mu \mathrm{g} / \mathrm{mL}$ pure double stranded DNA (dsDNA).

\section{DNA Concentration $(\mu \mathrm{g} / \mathrm{mL})=(\mathrm{A} 260-\mathrm{A} 320) \times \mathrm{DF} \times 50$}

The ratio $260 / 280$ was measured to evaluate DNA purity, according to the formula:

\section{Purity "=" "Optic density at $260 \mathrm{~nm} / /$ "Optic density at $280 \mathrm{~nm} "$}

Good-quality DNA has an A260/A280 ratio of 1.7-2. A reading of 1.6 does not render the DNA unsuitable for any application, but if the ratio isappreciably lower, it may indicate the presence of protein, 
Citation: Tabbouny SB, Chamoun E, Pavliuchenko N, Bassil M (2017) Oxidative Stress Levels in Buccal Cells Using MAWI Collection Tubes. J Pharmacovigil 5: 225. doi:10.4172/2329-6887.1000225

Page 3 of 6

phenol or other contaminants that absorb strongly at or near $280 \mathrm{~nm}$. High ratios may indicate the contamination of RNA.

DNA quality assessment by gel electrophoresis: The amount and integrity of DNA was determined visually after electrophoresis on a 1 $\%$ agarose gel containing ethidium bromide. The size of the DNA was determined by a comparison with DNA ladder. Images were captured using Versa Doc Imaging System.

\section{DNA damage assessment by BPDE-DNA adduct}

A commercial ELISA kit [OxiSelect ${ }^{\text {tw }}$ BPDE DNA Adduct ELISA Kit (Lot \#030320161)] for rapid detection of BPDE-DNA adducts was evaluated.

Briefly, $50 \mu \mathrm{L}$ of the unknown DNA samples and BPDE-DNA standards were added to the wells of the DNA High Binding plate; each DNA sample was assayed in duplicate. DNA Binding Solution was added to each well and incubated overnight on an orbital shaker. Then, we added Assay Diluent. Diluted Anti-BPDE-I Antibody was incubated for $1 \mathrm{~h}$ on an orbital shaker. Samples were washed 5 times with 1X Wash Buffer. Then, diluted Secondary Antibody-HRP Conjugate was incubated for 1 hour on an orbital shaker; and the same procedure of washing was repeated. The enzyme reaction was developed by the addition of $3,3^{\prime}, 5,5^{\prime}$-Tetramethylbenzidine (TMB) Substrate to each well. The enzyme reaction was stopped after $10 \mathrm{mints}$ and $30 \mathrm{~s}$ by the addition of Stop Solution. The plates were read on a microplate reader (model 340PC384, SpectraMax Pro 6.4 Software, Molecular Devices), and the absorbance at $450 \mathrm{~nm}$ was recorded.

\section{Results}

The academic subgroups showed a high purity of extracted DNA. The first extraction (subgroup A) yielded a mean of DNA of 8.774 $\mu \mathrm{g} / \mathrm{mL}$, and the second (subgroup B) yielded a mean of $10.032 \mu \mathrm{g} / \mathrm{mL}$ Tables 1 and 2 show the purities and concentrations of DNA obtained ( $\mu \mathrm{g} \mathrm{DNA} / \mathrm{mL}$ ) from each sample.

\begin{tabular}{|l|l|l|}
\hline \multicolumn{3}{|c|}{ Extracted DNA (Average of 3) } \\
\hline Sample & Concentration $(\boldsymbol{\mu g} / \mathrm{mL})$ & Purity (A260/A280) \\
\hline 1A & 7.6 & 1.822 \\
\hline 2A & 16.96 & 1.763 \\
\hline 3A & 7.34 & 1.783 \\
\hline 4A & 6.782 & 1.862 \\
\hline 5A & 12.228 & 1.977 \\
\hline 6A & 8.867 & 1.878 \\
\hline 8A & 7.58 & 1.849 \\
\hline 9A & 5.812 & 1.845 \\
\hline 1B & 6.36 & 1.941 \\
\hline 2B & 8.215 & 1.885 \\
\hline
\end{tabular}

Table 1: Assessment of concentrations and purities of extracted DNA from samples taken from the Faculty of Science, Lebanese University, Rafic Hariri University Campus, Lebanon (Subgroup A).

\begin{tabular}{|l|l|l|}
\hline \multicolumn{3}{|c|}{ Extracted DNA (Average of 3) } \\
\hline Sample & Concentration $(\boldsymbol{\mu g} / \mathrm{mL})$ & Purity (A260/A280) \\
\hline 3B & 8.442 & 1.877 \\
\hline 4B & 9.28 & 1.841 \\
\hline 5B & 4.453 & 1.883 \\
\hline 6B & 14.887 & 1.962 \\
\hline 8B & 7.377 & 1.918 \\
\hline 9B & 7.677 & 1.903 \\
\hline 10B & 5.997 & 1.908 \\
\hline 1C & 11.868 & 1.86 \\
\hline 2C & 8.397 & 1.927 \\
\hline 4C & 21.937 & 1.881 \\
\hline
\end{tabular}

Table 2: Assessment of concentrations and purities of extracted DNA samples taken from the Faculty of Science, Lebanese University, Fanar Campus, Lebanon (Subgroup B). Sample 4C is obviously not just DNA, and the high concentration may be due to the presence of nicotine.

The volume of sample taken for the DNA extraction was $200 \mu \mathrm{L}$ for the subgroup A and $250 \mu \mathrm{L}$ for the subgroup B. It didn't affect the DNA yield. In fact, the concentrations of DNA in the subgroup B weren't significantly higher than the subgroup A DNA was loaded on a $1 \%$ agarose gel to check integrity and degradation (Figures 2 and 3). DNA of all subjects of the academic subgroups was fairly good and not degraded but the amount was a bit low.

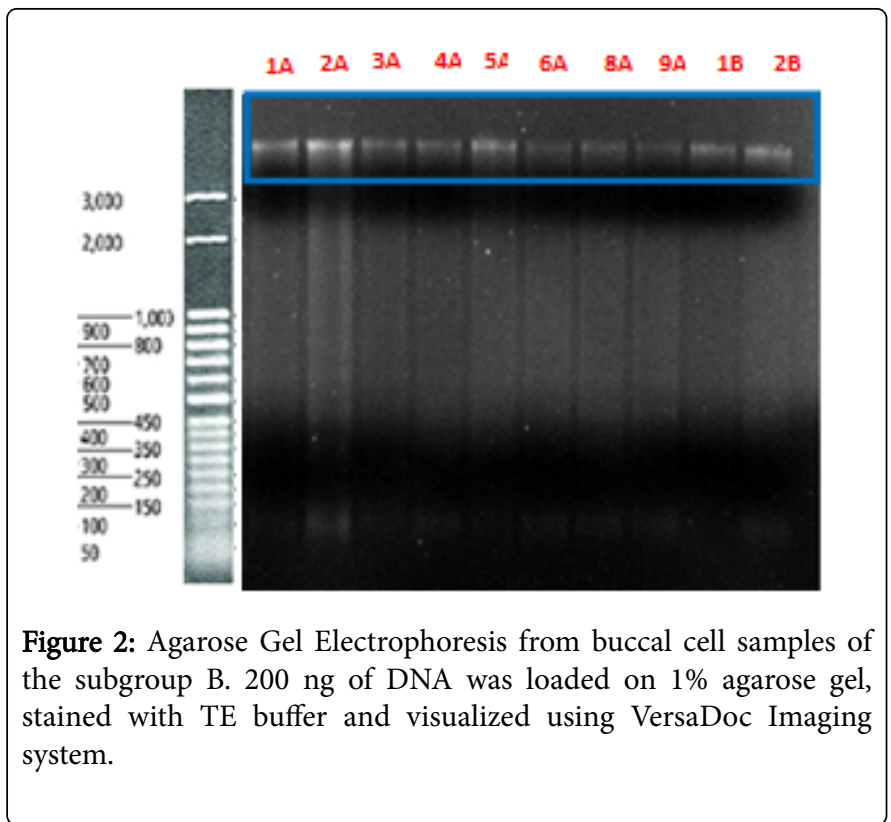


Citation: Tabbouny SB, Chamoun E, Pavliuchenko N, Bassil M (2017) Oxidative Stress Levels in Buccal Cells Using MAWI Collection Tubes. J Pharmacovigil 5: 225. doi:10.4172/2329-6887.1000225

Page 4 of 6

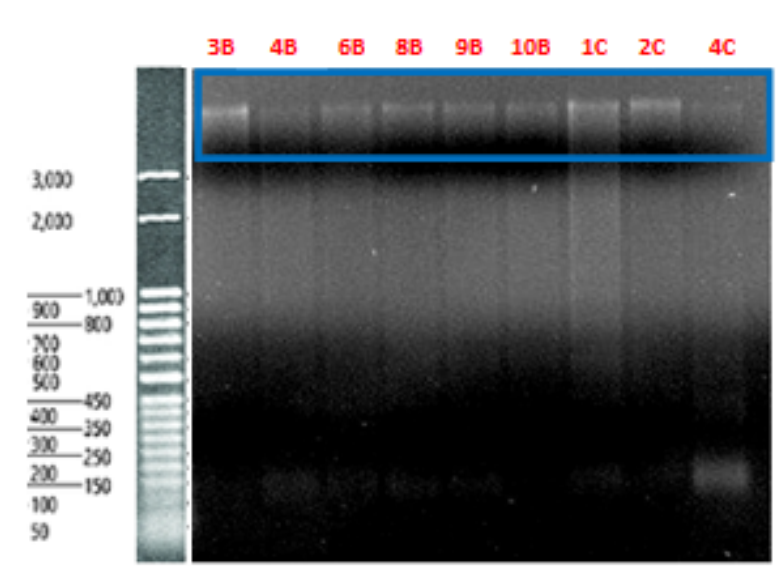

Figure 3: Agarose Gel Electrophoresis from buccal cell samples of the subgroup A. $200 \mathrm{ng}$ of DNA was loaded on $1 \%$ agarose gel, stained with TE buffer and visualized using VersaDoc Imaging system.

Results of the industrial subgroups showed a high purity of the extracted DNA $(1.7 \leq$ A260/A280 ratios $\leq 2)$. The first extraction (subgroup C) yielded a mean of $25.394 \mu \mathrm{g} / \mathrm{mL}$ of DNA, and the second one (subgroup D) yielded a mean of $18.112 \mu \mathrm{g} / \mathrm{mL}$. Tables 3 and 4 show the purities and concentrations of DNA obtained ( $\mu \mathrm{g} \mathrm{DNA} / \mathrm{mL})$ from each sample. The volume of sample taken for the DNA extraction was $250 \mu \mathrm{L}$ for the 2 industrial subgroups. Figures 4 and 5 show the results of agarose gel electrophoresis for the industrial subgroups. The amount of DNA was mainly good, not degraded, and the bands were clear and didn't show smears.

\begin{tabular}{|c|c|c|}
\hline \multicolumn{3}{|c|}{ Extracted DNA (Average of 3) } \\
\hline Sample & Concentration $(\mu \mathrm{g} / \mathrm{mL})$ & Purity (A260/A280) \\
\hline $3 C$ & 17.098 & 1.992 \\
\hline $5 C$ & 33.932 & 1.883 \\
\hline $6 C$ & 27.832 & 1.958 \\
\hline $8 \mathrm{C}$ & 35.273 & 1.968 \\
\hline $10 \mathrm{C}$ & 21.182 & 1.862 \\
\hline 1D & 17.957 & 1.958 \\
\hline $2 \mathrm{D}$ & 26.218 & 1.975 \\
\hline $4 \mathrm{D}$ & 25.155 & 1.929 \\
\hline $6 \mathrm{D}$ & 35.657 & 2.006 \\
\hline $8 \mathrm{D}$ & 13.635 & 1.923 \\
\hline
\end{tabular}

Table 3: Assessment of concentrations and purities of extracted DNA from samples taken from Benta Pharma Industries BPI, Dbayeh, Lebanon (Subgroup C).

\begin{tabular}{|l|l|l|}
\hline \multicolumn{2}{|l|}{ Extracted DNA (Average of 3) } & \multicolumn{2}{l|}{} \\
\hline Sample & Concentration $(\boldsymbol{\mu g} / \mathrm{mL})$ & Purity (A260/A280) \\
\hline 9D & 16.33 & 1.905 \\
\hline $10 D$ & 15.95 & 1.826 \\
\hline $1 E$ & 32.71 & 1.962 \\
\hline $2 E$ & 13.14 & 1.855 \\
\hline $3 E$ & 31.7 & 1.941 \\
\hline $4 E$ & 18.26 & 1.997 \\
\hline $5 E$ & 11.12 & 1.896 \\
\hline $6 E$ & 9.47 & 1.923 \\
\hline $7 E$ & 21.27 & 1.875 \\
\hline $8 E$ & 11.17 & 2.019 \\
\hline
\end{tabular}

Table 4: Assessment of concentrations and purities of extracted DNA from samples taken from Benta Pharma Industries BPI, Dbayeh, Lebanon (Subgroup D).

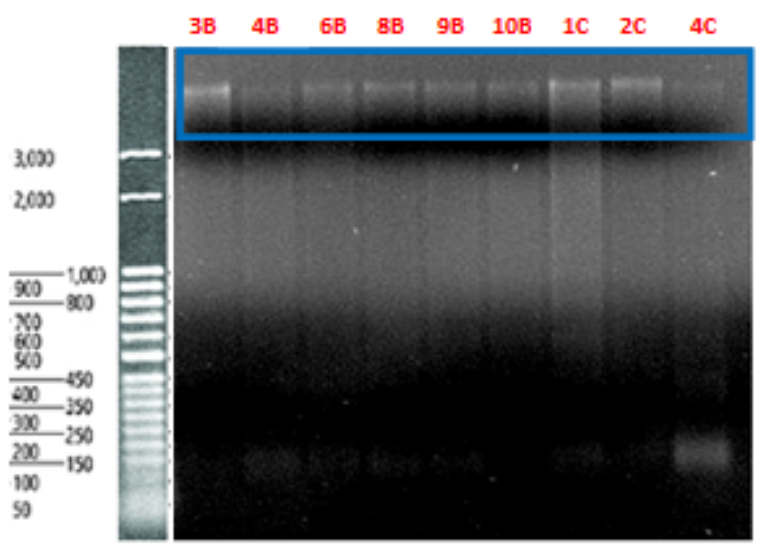

Figure 4: Agarose Gel Electrophoresis from buccal cell samples of the subgroup C. $200 \mathrm{ng}$ of DNA was loaded on $1 \%$ agarose gel, stained with TE buffer and visualized using VersaDoc Imaging system. In wells $3 \mathrm{C}, 6 \mathrm{C}$ and $8 \mathrm{C}$, the bands were less clear than the others, due to the fact that some of the loaded volume spilled out of the wells. 


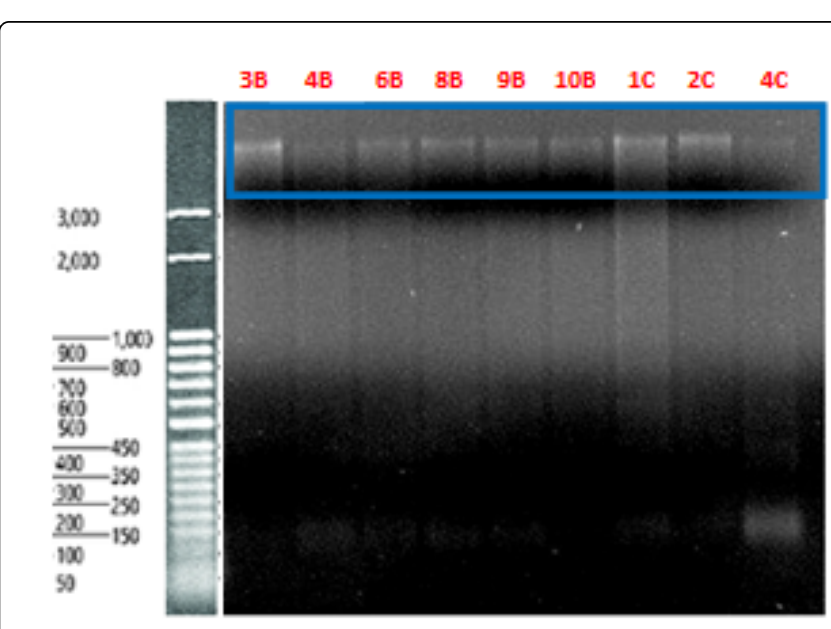

Figure 5: Agarose Gel Electrophoresis from buccal cell samples of the subgroup D. $200 \mathrm{ng}$ of DNA was loaded on $1 \%$ agarose gel, stained with TE buffer and visualized using VersaDoc Imaging system. The well $2 \mathrm{E}$ showed a light band because the tip accidently fell on the DNA while adding the loading buffer, which probably caused a loss of DNA. The well $5 \mathrm{E}$ also showed a light band due to the fact that some of the volume was loaded outside the well.

To sum up the extraction, buccal DNA yields showed a very broad zone with values as low as $4.453 \mu \mathrm{g} / \mathrm{mL}$ to as high as $35.657 \mu \mathrm{g} / \mathrm{mL}$.

DNA damage was assessed using the OxiSelect" BPDE DNA Adduct ELISA Kit. In order to determine the levels of BPDE adducts in the unknown samples, a standard curve was prepared using different concentrations of BPDE-DNA (Figure 6). The r2 value was 0.999, indicating that OD450 is an effective method to monitor color development.

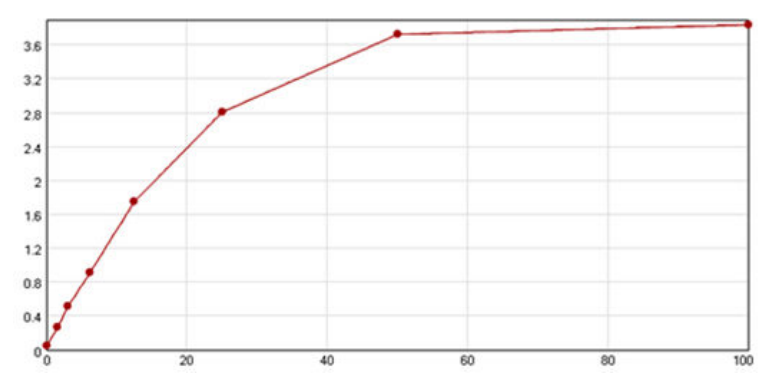

Figure 6: Standard curve showing the absorbances of different BPDE-DNA concentrations $(n=2)$. The different BPDE-DNA concentrations were $0 ; 1.56 ; 3.13 ; 6.25 ; 12.5 ; 25 ; 50$ and $100 \mu \mathrm{g} / \mathrm{mL}$. The equation of the standard curve was: $\mathrm{y}=1 \mathrm{E}-05 \mathrm{x} 3-0.002 \mathrm{x} 2+$ $0.162 \mathrm{x}+0.024$; with $\mathrm{r}^{2}=0.999$.

To determine the amount of BPDE-DNA damage, a 96-well plate layout is shown in Figure 7. The amount of BPDE-DNA damage in the unknown samples was very low (lower than $1.56 \mu \mathrm{g} / \mathrm{mL}$ ), indicating the absence of BPDE-DNA damage in the unknown DNA samples. This can be explained by the presence of a non-oxidized DNA.



Figure 7: 96-Well plate layout to determine unknown samples' concentrations. Each sample was assayed in duplicate. The first two columns represent the standard curve: Wells A1 A2; B1 B2; C1 C2; D1 D2; E1 E2; F1 F2; G1 G2; and H1 H2 represent simultaneously $100 ; 50 ; 25 ; 12.5 ; 6.25 ; 3.13 ; 1.56$; and $0 \mu \mathrm{g} / \mathrm{mL}$ of BPDE-DNA. The columns 3-12 represent the unknown samples: Wells A3 A4; B3 B4; C3 C4; D3 D4; E3 E4; F3 F4; G3 G4; H3 H4; A5 A6; B5 B6 represent simultaneously the samples $1 \mathrm{~A} ; 2 \mathrm{~A} ; 3 \mathrm{~A} ; 4 \mathrm{~A} ; 5 \mathrm{~A} ; 6 \mathrm{~A} ; 8 \mathrm{~A} ; 9 \mathrm{~A} ; 1 \mathrm{~B} ; 2 \mathrm{~B}$ of the subgroup A. Wells C5 C6; D5 D6; E5 E6; F5 F6; G5 G6; H5 H6; A7 A8; B7 B8; C7 C8; D7 D8 represent simultaneously the samples $3 \mathrm{~B} ; 4 \mathrm{~B} ; 5 \mathrm{~B} ; 6 \mathrm{~B} ; 8 \mathrm{~B} ; 9 \mathrm{~B} ; 10 \mathrm{~B} ; 1 \mathrm{C} ; 2 \mathrm{C} ; 4 \mathrm{C}$ of the subgroup $\mathrm{B}$. Wells E7 E8; F7 F8; G7 G8; H7 H8; A9 A10; B9 B10; C9 C10; D9 D10; E9 E10; F9 F10 represent simultaneously the samples 3C; 5C; 6C; 8C; 10C; 1D; 2D; 4D; 6D; 8D of the subgroup C. Wells G9 G10; H9 H10; A11 A12; B11 B12; C11 C12; D11 D12; E11 E12; F11 F12; G11 G12; H11 H12 represent simultaneously the samples 9D; 10D; $1 \mathrm{E} ; 2 \mathrm{E} ; 3 \mathrm{E} ; 4 \mathrm{E} ; 5 \mathrm{E} ; 6 \mathrm{E} ; 7 \mathrm{E} ; 8 \mathrm{E}$ of the subgroup D.

\section{Discussion}

In the DNA sampling, the academic and industrial subgroups showed a high purity of extracted DNA. In fact, pure DNA preparations have expected A260/A280 ratios of 1.7-2. The industrial subgroups showed higher DNA concentrations compared to the academic subgroups. It is important to mention that in some MAWI tubes, cotton strings were observed, which made the pipetting harder. This can be the cause of the high DNA concentrations.

In the DNA extraction, buccal DNA yields showed a very broad zone with values as low as $4.453 \mu \mathrm{g} / \mathrm{mL}$ to as high as $35.657 \mu \mathrm{g} / \mathrm{mL}$, which is mainly expected from the claims of the MAWI manufacturers. High DNA yields in buccal samples is mainly due to the performance of the lysis buffer present in the MAWI tubes, however, our results were lower than those obtained with other studies using one foam swab (Puritan Medical Products Co, Guilford, ME) [8]. This can be due to the fact that the swabbing was insufficient or the usage of more than one swab for buccal cell collection was needed. It is worth mentioning that in a previous study, comparing DNA collection and retrieval from two swab types: cotton and flocked swab when processed using three QIAGEN extraction methods: QIAcube, BioRobot EZ1 and manually processed QIAamp DNA investigator kit; the obtained results indicated that the cotton swab combined with the spin-column extraction was shown to be the most effective method [9].

In order to assess the levels of BPDE adducts, we used the OxiSelect ${ }^{\text {m" }}$ BPDE DNA Adduct ELISA Kit. The amount of BPDE-DNA damage in the unknown samples was as the blank of our standard curve, which indicates the absence of BPDE adducts in the unknown 
DNA samples. It can be possibly concluded that MAWI tubes may not be able to preserve oxidative stress, since none of the samples showed aBPDE-DNA damage. Moreover, DNA integrity was evaluated and we did not find signs of degradation.

In conclusion, the detection of BPDE in human cells [10,11], the fact that buccal cells are one of the common biological sources of DNA for adduct analysis $[12,13]$ and the stability of BPDE-DNA damage in human cells [14-16] in previous studies including our results suggest that MAWI collection tubes cannot preserve BPDE-DNA damage and may not be able to allow the detection of oxidative stress. Other oxidative stress markers should be used to evaluate the previous statement.

\section{Acknowledgment}

We would like to thank Dr. Mazen Kurdi for his help in providing the study with the OxiSelect ${ }^{\text {m" }}$ BPDE DNA Adduct ELISA Kit. Our sincere thanks also goes to the volunteers from the Faculty of Science, Lebanese University, Rafic Hariri University Campus, Hadath, Lebanon and the Faculty of Science, Lebanese University, Fanar Campus, Lebanon and from Benta Pharma Industries BPI, Dbayeh, Lebanon. Without their precious support it would not be possible to conduct this research. I also thank Benta Biotech department for the secretarial assistance with this manuscript.

\section{References}

1. Smith JA, Park S, Krause JS, Banik NL (2013) Oxidative stress, DNA damage, and the telomeric complex as therapeutic targets in acute neurodegeneration. Neurochem Int 62: 764-775.

2. Geneste O, Camus AM, Castegnaro M (1991) Comparison of pulmonary DNA adduct levels, measured by 32P-postlabeling and aryl hydrocarbon hydroxylase activity in lung parenchyma of smokers and ex-smokers. Carcinogenesis 12: 1301-1305.

3. Izzotti A, Rossi GA, Bagnasco M, De Flora S (1991) Benzo(a)pyrene diolepoxide-DNA adducts in alveolar macrophages of smokers. Carcinogenesis 12: 1281-1285.

4. Thanan R (2015) Oxidative Stress and Its Significant Roles in Neurodegenerative Diseases and Cancer. Int J Mol Sci 16: 193-217.
5. Yan S (2014) Functional interplay between ATM/ATR-mediated DNA damage response and DNA repair pathways in oxidative stress. Cell Mol Life Sci 71: 3951-3967.

6. Cadet J (2012) Biologically relevant oxidants and terminology, classification and nomenclature of oxidatively generated damage to nucleobases and 2-deoxyribose in nucleic acids. Free Radical Research 46: 367-381.

7. Livy A (2012) Evaluation of Quality of DNA Extracted from Buccal Swabs for Microarray Based Genotyping. Ind J Clin Biochem 27: 28-33.

8. Rogers N, Cole S, Lan HC, Crossa A, Demerath E (2007) New Saliva DNA Collection Method Compared to Buccal Cell Collection Techniques for Epidemiological Studies. Am J Hum Biol 19: 319-326.

9. Brownlow R, Dagnall K, Ames C (2012) A Comparison of DNA Collection and Retrieval from Two Swab Types (Cotton and Nylon Flocked Swab) when Processed Using Three QIAGEN Extraction Methods. J Forensic Sci 57: 713-717.

10. Xu X, Bai L, Chen W, Padilla M, Liu Y, et al. (2012) MUC1 Contributes to BPDE-Induced Human Bronchial Epithelial Cell Transformation through Facilitating EGFR Activation. PLOS One 7.

11. Neal J, Fletcher K, McCormick J, MaherV (2010) The role of hRev7, the accessory subunit of $\mathrm{hPol} \zeta$, in translesion synthesis past DNA damage induced by benzo[a]pyrene diol epoxide (BPDE). BMC Cell Biol 11: 97.

12. Tretyakova N, Villalta P, Kotapati S (2013) Mass Spectrometry of Structurally Modified DNA. Chem Rev 113: 2395-2436.

13. Tretyakova N, Goggin M, Sangaraju D, Janis G (2012) Quantitation of DNA Adducts by Stable Isotope Dilution Mass Spectrometry. Chem Res Toxico 25: 2007-2035.

14. Lu X, Liu Y, Yu T, Xiao S, Bao X, et al. (2013) ERCC1 and ERCC2 Haplotype Modulates Induced BPDE-DNA Adducts in Primary Cultured Lymphocytes. PLOS One 8.

15. Ikejiri AT, Somaio Neto F, Chaves JC, Bertoletto PR, Teruya R, et al. (2014) Gene expression profile of oxidative stress in the lung of inbred mice after intestinal ischemia/reperfusion injury. Acta Cir Bras 29: 186-192.

16. Sipinen V, Laubenthal J, Baumgartner A, Cemeli E, Linschooten JO, et al. (2010) In vitro evaluation of baseline and induced DNA damage in human sperm exposed to benzo[a]pyrene or its metabolite benzo[a]pyrene-7,8-diol-9,10-epoxide, using the comet assay. Mutagenesis 25: 417-425. 